\title{
Jovens Autonomistas do Centro de Mídia Independente e o Velho Vestido de Novo
}

\author{
Youngsters Autonomists of the Independent Media Center and the Old
}

Dressed in New

http://dx.doi.org/10.5007/2178-4582.2013v47n1p50

\section{Carlos André dos Santos}

Escola de Ensino Básico Cecília Rosa Lopes, São José/SC, Brasil

Eu estava sobre uma colina e vi o Velho se aproxmando, mas ele vinha como se fosse o Novo. Ele se arrastava em novas muletas, que ninguém antes havia visto, e exalava novos odores de putrefação, que ninguém antes havia cheirado. (...)

E em torno estavam aqueles que instilavam horror e gritavam: Ai vem o Novo, tudo é novo,

saúdem o Novo, sejam novos como nós!

Trechos de Parada do Velho Novo - Bertold Brecht

\begin{abstract}
Esse artigo trata a participação política dos jovens em ações coletivas de contestação ao estabelecido na mídia radical alternativa, tendo sido desenvolvido por meio de um estudo de caso das atividades do Centro de Mídia Independente no Brasil. Nosso objetivo foi expor as interações e reconfigurações do ativismo juvenil, suas possibilidades e também limites, dado que a contestação ao estabelecido está submetida aos percalços dos mecanismos onde o "velho", se apresenta como "novo", mantendo o objetivo de manutenção e adaptação dos jovens ao sistema de produção capitalista.
\end{abstract}

Palavras chave: Jovens - Mídia radical alternativa - Participação política.
This paper is about the youngsters' political participation in collective actions that challenge the establishment by the radical alternative media. It was developed through a case study on the activities of the Independent Media Center in Brazil. Our goal is to present the interactions and reconfigurations of the youth activism, as well as its possibilities and limits, once the challenge of the established is subject to the mishaps of mechanisms where the "old" is presented as "new", whereas its purpose of maintaining and adapt the youth to the capitalist system of production is kept unchanged.

Keywords: Youngsters - Radical alternative media - Political participation.

Este artigo, desenvolvido a partir de um longo estudo qualitativo materializado na dissertação Os Olhos por trás das Lentes (SANTOS, 2010), tem como objetivo expor as interações e reconfigurações do ativismo juvenil, suas possibilidades e também limites, dado que a contestação ao estabelecido está submetida aos percalços de mecanismos onde o "velho" se apresenta como "novo", mantendo inalterado o de objetivo de manter e adaptar os jovens ao sistema de produção capitalista.

Os estudos foram realizados no Núcleo de Pesquisa sobre a Juventude Contemporânea (NEJUC/UFSC) e tiveram como sujeitos de pesquisa jovens 
ativistas do Centro de Mídia Independente no Brasil (CMI), um dos enlaces da rede mundial Indymedia de coletivos de produtores e produtoras de mídia radical alternativa (DOWNING, 2003). Essa mídia alternativa utiliza tecnologias de informação como parte de seu ativismo e forma de organização, a fim de suprir a necessidade social e política de oferecer livre acesso à troca de informações e produção cultural, à livre associação e, sobretudo, de construir soluções frente ao monopólio dos meios de comunicação de massa.

A pesquisa traz à tona os sentidos que os jovens participantes do CMI atribuem à sua participação política, e o uso de métodos qualitativos na pesquisa (entrevistas semiestruturadas, análise de documentos e produções áudios-visuais) nos permitiu visualizar não só a existência de uma política difusa não institucionalizada na juventude, como também, as trajetórias de sujeitos políticos em diferentes situações e conjunturas ao longo dos últimos 13 anos.

$\mathrm{Na}$ última década, conforme Sousa (2003, p.3), os estudos sobre a juventude "vêm se atualizando na compreensão das novas sociabilidades históricas inter-relacionadas com categorias sociais, culturais e políticas", o que demonstra, segundo esta autora, o desafio enfrentado pelas novas gerações de contestadores. Isto porque o comportamento juvenil atual evidencia que as instituições contam com os jovens para seus projetos, integrando-os em grupos controlados por adultos, o que não anula nem neutraliza a sua capacidade de autonomia, de questionar o "velho" e de organizar-se politicamente.

O debate proposto por Sousa (Ibid.) sugere ser interessante distinguir o conceito de política, na dimensão da esfera institucional, daquelas políticas que frequentam os espaços de experiência social, gerando novas sociabilidades. Ainda que vago e impreciso, este conceito de política ajuda a compreender a ação juvenil contemporânea, onde se verifica a tendência de insurgências indicadas em ações contra instituintes.

Nesse sentido, para analisar de forma crítica as possibilidades e limites de contestação ao estabelecido, protagonizado pela juventude, levamos em conta que cada época histórica define seus conflitos de maneira diferente no interior de suas linhas de força; e se posiciona através de uma perspectiva geracional particular, situação em que se vivencia a experiência social de formas distintas. Mais do que comparar gerações, há de se comparar sociedades onde convivem diferentes gerações (URRESTI, 2000).

As revoltas dos jovens nas ruas de Seattle, Gênova, Praga, Argentina, Chile, México, nos subúrbios de Paris, Londres e na Grécia são expressões do fazer e do poder político juvenil hoje. Como demonstram os trabalhos de Feixa (2006), Groppo (2005) e Sousa (2003), tais movimentos não podem ser comparados simplesmente por seu grau de eficiência em relação aos eventos protagonizados por gerações anteriores, pois seus desafios, limites, possibilidades e acessos aos recursos materiais e imateriais são inerentes às múltiplas realidades, experiências e aos imaginários políticos de sua época.

Para Sousa (2003), existe a presença dessa política difusa e não institucionalizada: nas periferias do Brasil, se referindo aos jovens contestadores do 
movimento Hip Hop; no movimento estudantil e nos jovens que atuam politicamente organizados em redes, como o Centro de Mídia Independente; em movimentos como o Movimento Passe Livre, nos coletivos feministas, ecologistas radicais, de liberação animal. De forma coletiva ou individualmente, esses jovens são receptivos às chamadas ações coletivas locais e globais.

Ao estudar o poder e o fazer político da juventude contestadora nos dias de hoje, nos deparamos com conteúdos políticos que nos remetem aos movimentos de maio de 1968, aos novos movimentos sociais e à radicalização das pautas da esquerda em geral, composta por movimentos sociais de base territorial e sindicatos. No entanto, não se trata de um transporte de modelos de ação de uma época para outra.

Os jovens contestadores de hoje atuam criativamente reelaborando suas práticas políticas em um sistema de produção da riqueza social cada vez mais eficaz em capturar seus opositores. As novas sociabilidades políticas são respostas à facticidade do mundo da vida, ou seja, têm como base condições históricas concretas, comuns a todas as pessoas e que são atravessadas por uma série de variáveis social e culturalmente construídas; situadas espacial e temporalmente, ainda que flexíveis.

Nos últimos 30 anos, a globalização neoliberal corresponde a um novo regime de acumulação de capital, mais globalizado do que nos períodos anteriores, e que visa, por um lado, à desregulamentação total do mercado, desvinculando-o de qualquer controle social e político e, por outro, acentuar a lei do valor como forma de organizar a sociedade, pressupondo que toda atividade social se organiza melhor sob a forma de mercado (SANTOS, 2005).

As mudanças no papel do Estado, do mercado e da sociedade civil, sob égide hegemônica da ideologia neoliberal e de sua agenda política - formulada pelos países ricos, reformadores corporativos - vieram acompanhadas de arranjos internacionais de guerra contra a fome, ao tráfico de drogas e ao terrorismo, o que leva, ainda hoje, os Estados Nacionais a suprimirem direitos dos povos e a assumirem de forma antidemocrática essa agenda. Não obstante, ao processo desencadeado pela ideologia neoliberal está o desenvolvimento das tecnologias de informação.

As redes sociais, que sempre existiram ao longo desse período, foram potencializadas pelas tecnologias de informação, tornando-se ferramentas indispensáveis à produção de bens e mercadorias, ao exercício do poder e à criação de códigos culturais. Ao mesmo tempo que nos deparamos com a passagem do capitalismo industrial para o capitalismo informacional, fixado nos meios de difusão da cultura e na informação (CASTELLS, 1999; HARDT; NEGRI, 2001).

No capitalismo qualificado como informacional (HARDT; NEGRI, 2001), os setores de comunicação, cultura e informação se apresentam como o modelo mais rico de produção, por impulsionarem o setor de serviços e por se constituírem, basicamente, pela permuta contínua de informações e conhecimentos característicos do trabalho imaterial. Estes autores argumentam que no trabalho imaterial - ou seja, o trabalho que produz bens imateriais, como serviços, produtos culturais, conhecimento ou comunicação - a cooperação é 
totalmente inerente ao trabalho. $\mathrm{O}$ aspecto cooperativo do trabalho imaterial não é imposto e organizado de fora, como em formas anteriores de trabalho, mas envolve de imediato a interação e a cooperação social.

Inerente ao processo de pós-modernização da economia é sua forma de estratificação social e adaptação, tendo em vista que o capitalismo informacional não é a superação do capitalismo, mas sim um sistema que exige dos indivíduos certa autonomia para funcionarem como terminais do alto fluxo de informação, ao mesmo passo que impõe adaptações, por meio do poder disciplinar e de novas formas de controle.

O processo da globalização neoliberal e a presença tentacular das redes sociais na produção da riqueza social e dos códigos culturais desencadearam também novas formas de resistência, nas quais é possível identificar uma multiplicidade de sujeitos coletivos e individuais, que se distinguem entre si do ponto de vista revolucionário. Por um lado, temos aqueles que convergem para ações coletivas, que visam responder aos ataques do capital sob identidades políticas que legitimam o Estado para obter avanços na redistribuição da riqueza social sem ruptura com o capitalismo. Por outro lado, os sujeitos coletivos e individuais que, por meio de experiências de autogestão, ação direta e de um novo internacionalismo marcado pela ausência de um projeto único, buscam a transformação radical de sociedade.

Apesar de ambos os sujeitos - coletivos e individuais - convergirem em campanhas, protestos e outras ações coletivas contra o estabelecido, o primeiro grupo - onde situamos os sindicatos reformistas, a social democracia, os partidos políticos e as ONGs que ora se filiam às políticas progressistas, ora às políticas neoliberais (HARVEY, 2010) - é limitado do ponto de vista da emancipação, devido à sua subordinação às políticas de seus mantenedores e financiadores.

O segundo grupo é composto por movimentos sociais de base territorial que lutam por terra e moradia, sindicatos radicais e movimentos identitários, e por parte de uma juventude que constrói sua participação política contestando os ciosos donos do poder por meio da autogestão e ação direta. Mas isso não significa que estão isentos de serem capturados pelo capital.

\section{Como surgiu o Centro de Mídia Independente?}

O primeiro Indymedia nasceu em outubro de 1999, quando jornalistas independentes, ativistas de software livre e redes de mídia independente - como a Freespeeche.org ${ }^{l}$, Protest. Net, Paper Tiger TV e Deep Dish TV - se dedicaram, em tempo integral, para criar um espaço midiático com as características utilizadas na organização dos protestos contra a reunião da Organização Mundial de Comércio (OMC), em novembro de 1999, na cidade de Seattle (JURIS, 2004). O objetivo destes protestos multicoloridos, ricos em diversidade tática

$1 \quad$ TV pública via satélite, com base em Denver, Colorado, fundada em 1995, mas sua história é anterior aos anos 90. Vive de doações e atualmente atinge mais de 25 mil de domicílios nos Estados Unidos. 
e de sujeitos coletivos contra a rodada do milênio da OMC foi barrar a aprovação do Tratado Multilateral de Investimentos (AMI), acordo internacional que pretendia ser a Constituição da nova economia unificada ${ }^{2}$. Muito diferente das formas de organização dos veículos de comunicação das organizações não governamentais (ONGs), sindicatos e da esquerda partidária, que foram cobrir as manifestações em Seattle reproduzindo os moldes da imprensa comercial, em que equipes de jornalistas profissionais eram responsáveis por produzir conteúdo, sintetizar as propostas e críticas das lideranças sobre os assuntos relacionados às pautas de suas respectivas organizações e por reportá-las ao público.

O primeiro coletivo Indymedia seguiu os princípios de autogestão e de horizontalidade dos movimentos sociais de base territorial, sindicatos radicais e coletivos autônomos, utilizando um software de publicação aberta, possibilitando, assim, a qualquer pessoa hospedar na internet os vídeos, fotos, áudio e textos sobre as manifestações, sem a necessidade de um especialista e registro de IP.

$\mathrm{O}$ uso das ferramentas tecnológicas interativas no Independent Media Center (Indymedia) emerge como uma possibilidade de construir uma esfera pública não institucionalizada ou colonizada pelos interesses do mercado e Estado. Sintetizando a proposta, a democratização da mídia, para a rede CMI, não passa apenas pela necessidade de responder aos discursos hegemônicos; é preciso que as vozes dos manifestantes sejam ouvidas e que suas diferenças culturais e sociais sejam respeitadas. A melhor maneira para que isso aconteça é que os manifestantes sejam os próprios interlocutores com o público, sem a padronização presente na mídia comercial e as hierarquizações geradas pelo padrão jornalístico.

De acordo com a página do grupo de trabalho do CMI, entre 2000 e 2008, existiam 170 coletivos espalhados por todo mundo. No Brasil, entre $2001 \mathrm{e}$ 2008, eram 12 coletivos em diferentes graus de atividade, nas cidades de Belo Horizonte, Brasília, Campinas, Florianópolis, Fortaleza, Goiânia, Joinville, Porto Alegre, Rio de Janeiro, Tefé, Salvador e São Paulo. Haviam também 16 "pré-coletivos", nome dado aos coletivos em processo de ingresso na rede, em diferentes graus de atividade.

Os coletivos locais são subdivididos por cidades, regiões e temáticas e organizados em redes descentralizadas, em que os pontos nodais (ou seja, os coletivos) decidem de forma autônoma suas atividades e assumem o compromisso de manter a horizontalidade nos processos de decisão. Esses coletivos não aceitam financiamentos de empresas ou do Estado e não reproduzem, internamente - isto é, nos coletivos e em suas matérias - preconceitos em relação a gênero, orientação sexual, etnia, nacionalidade ou classe.

Conforme a descrição feita por seus voluntários e voluntárias, sua proposta é "dar voz a quem não têm voz, constituindo uma alternativa consistente à

2

Os pontos mais sinistros do AMI apontados pelos membros da sociedade civil organizada e intelectuais estavam na: 1) a desobrigação dos investidores estrangeiros com as consequências de seus investimentos; ao mesmo tempo, o tratado garantia que os investidores estrangeiros teriam os mesmos direitos que os investidores nacionais; 2) a proibição de nacionalizações ou de expropriações de empresas para assegurar o emprego ou a soberania nacional, a flexibilização dos direitos sociais dos trabalhadores e de leis relativas ao meio ambiente e abolição de qualquer controle governamental sobre a transferência dos lucros e outros valores provenientes de investidores estrangeiros. 
midia empresarial, que frequentemente distorce fatos e apresenta interpretações de acordo com os interesses das elites econômicas, sociais e culturais." (CMI, 2013). Contudo, o objetivo da rede Indymedia vai além da descrição acima, correspondendo à intensa troca de significados e à construção de solidariedades entre os ativistas de mídia, movimentos sociais, comunitários e contraculturais.

A experiência de mídia radical alternativa - termo que define " [...] a utilização dos recursos da comunicação midiatizada em pequena escala para expressar uma visão alternativa às políticas, prioridades e perspectivas hegemônicas (DOWNING, 2002, p. 21)" - foi iniciada em Seattle, pelo Indymedia. Essa experiência assume escopo global com as possibilidades das tecnologias de informação adaptadas a um paradigma de democratização que busca romper com o padrão comunicador/especialista. Assim, converge para lógica autogestionada de enredar-se, entendida, como descreve Juris (2004, p.3), "como o princípio perfilado pela lógica do capitalismo informacional e que é interiorizada pelos ativistas, gerando práticas concretas de criação de redes."

$\mathrm{O}$ crescimento da rede Indymedia nos seus primeiros anos esteve ligado às ações coletivas e campanhas do movimento de resistência global ao capitalismo, pela circulação de informação, por voluntários e voluntárias de diferentes países em ações de protestos e encontros de ativistas. Nos Estados Unidos e no Canadá, após Seattle, muitos coletivos do CMI foram surgindo; primeiro em Portland, depois na Filadélfia e em Vancouver. Surgiram protestos contra a biotecnologia em Boston, em março de 2000, e protestos em Washington D.C. contra a reunião do Fundo Monetário Internacional (FMI), organizados por uma coalizão de movimentos estadunidenses, que colaborou para a construção da rede nestes locais. A manifestação em Praga contra o capitalismo, como resposta à reunião do FMI e Banco Mundial, em 2000, foi um dos eventos que marcaram a expansão da rede Indymedia pela Europa. Depois destes protestos, surgiram outros CMIs, em Madrid, Euskal Herria (País Basco) e Galícia.

O primeiro coletivo da rede Indymedia na América Latina foi no México, em junho de 2000, seguido pelo CMI Colômbia, em outubro, e do CMI Brasil, em dezembro do mesmo ano. O coletivo do CMI Bolívia, no entanto, se fragmentou e retomou suas atividades apenas em 2003, voltando a ser aprovado no processo de inclusão na rede, em 2004. Segundo o exaustivo trabalho de Behling (2006), entre 1999 e 2004, há um crescimento ascendente do número de coletivos do CMI, que possuem sites próprios na web: 106 coletivos, em 2002; 136, em 2003; e 162, em 2004. Em 2005, com 165 coletivos, o processo de formação de coletivos, com sites próprios, entra em fase de estabilização.

Behling (2006) explica que esta tendência não deve ser entendida por uma contemplação dos números de coletivos em relação aos sites, pois, muitos são formados utilizando os sites e recursos locais já existentes, como é o caso do CMI Renânia do Norte/Vesfália, que publicam no site alemão do Indymedia, e de alguns casos de coletivos na Itália. Há ainda coletivos locais que publicam em um site nacional, como é o caso do Brasil; regionais, como o CMI Oriente 
Médio e Indymedia Reino Unido; e do site continental CMI Oceania, que reúne os coletivos da Nova Zelândia, Indonésia, Austrália e Filipinas.

O CMI Argentina nasce em maio de 2001, com o intuito de cobrir as manifestações massivas na Argentina contra a reunião ministerial do Acordo de Livre Comércio das Américas (ALCA) em 5, 6 e 7 de abril, em Quebec. No entanto, o coletivo local vai ganhar mais fôlego, e sua página na Internet vai se tornar uma verdadeira ferramenta das lutas populares em novembro, em decorrência das massivas ações coletivas espontâneas e de desobediência civil, em meio à crise econômica e política desencadeada por anos de política neoliberal naquele país. Como observa Boido (2003) - pesquisador e voluntário do CMI Argentina - os protestos exaltam um novo protagonismo social, como o desconhecimento das representações da política tradicional, em que não só se questionam os sistemas político e econômico, mas também, os meios que os expressam.

Resumidamente, utilizando o levantamento realizado por Behling (2006), os dados da rede Latina e CMI Brasil e também os coletados nas entrevistas realizadas para o nosso estudo (SANTOS, 2010), podemos dizer que o processo de construção de um sistema de ação - em que um ator elabora expectativas e avalia as possibilidades e os limites de sua ação - exige capacidade de definir-se a si mesmo e ao seu ambiente (MELLUCI, 1999). Ele possui características distintas, estabelecidas pelas conexões entre os coletivos em rede e a complexa morfologia dos movimentos sociais contemporâneos.

Apesar de estarem em lugares distintos, de gozarem de recursos técnicos e materiais diferenciados e de atuarem em espaços movimentalistas com identidades e trajetórias diversas, os jovens voluntários e voluntárias do CMI estão conectados entre si por diversos espaços virtuais e reais. Neles é possível pensar as possibilidades e limites das práticas políticas, assim como é possível, para estes jovens, "contarem e sentirem parte de uma mesma história de rebeldia." (CECEÑA, 2003. p.10).

Para contarem e sentirem parte da mesma história de rebeldia, os sujeitos juvenis usam a palavra rebeldia como categoria política, tal como utilizada pelos zapatistas mexicanos. Ou seja, no sentido de que, ao contrário das experiências revolucionárias do século XX, estes sujeitos coletivos e individuais não se propõem a ser a única via anticapitalista para transformação radical da sociedade ou uma vanguarda. Eles se colocam como críticos da política representativa e chamam atenção para a necessidade de nos tornarmos "Mar$\cos$ ! [...] os intolerados buscando uma palavra, sua palavra. Todos aqueles e aquelas [...] que incomodam o poder e as boas consciências." (CARTAS E COMUNICADOS DEL EZLN, 1994).

Não é exagerado falar que, se a revolução cubana figura entre as principais fontes de imaginário rebelde para os jovens contestadores da geração de 1968, a experiência mais recente que nutriu e nutre a geração atual de ativistas, de práticas políticas e comunicacionais, constituintes de um imaginário de rebeldia, é o neozapatismo. Nele, é possível sentir-se parte da mesma história, tanto ao norte, quanto ao sul (CECEÑA, 2003), não só porque os neozapatistas colocaram 
em xeque as certezas neoliberais e da esquerda mundial, em relação ao papel do Estado, da revolução, das práticas e concepções políticas e do uso da mídia nos momentos de crise (HILSENBECK, 2005), mas, sobretudo, porque ofereciam generosamente alternativas de resistência ao capitalismo, sem impor um modelo único de como mudar o mundo.

\section{O CMI no Brasil}

No Brasil, o CMI foi criado em 2000, de um desdobramento das discussões entre coletivos autônomos em São Paulo que, na época, organizavam os protestos em 26 de setembro (S26), na cidade de São Paulo, simultâneos à reunião do FMI e Banco Mundial, que aconteceriam em Praga. O crescimento da rede CMI Brasil pode ser descrito em três ciclos, em que os voluntários e voluntárias atuaram não só como membros da rede CMI, mas como ativistas nas ações coletivas de contestação ao estabelecido devido à sua a múltipla militância.

O primeiro ciclo se inicia em 2000, com o surgimento do primeiro CMI em São Paulo e dos coletivos locais no Rio de Janeiro, Porto Alegre, Belo Horizonte e Campinas. Ele era caracterizado pela atuação dos coletivos locais em campanhas e protestos contra o Acordo de Livre Comércio das Américas, nos encontros de ativistas do Brasil e do Mundo nos espaços alternativos do Fórum Social Mundial, em Porto Alegre, que proporcionaram também uma aproximação com o movimento de rádios livres. O período corresponde à visibilidade de participação política juvenil autonomista, constituída pela adesão de jovens adeptos da contracultura punk e do movimento estudantil independente, as campanhas e ações coletivas do movimento de resistência global ao capitalismo.

Os voluntários e voluntárias do CMI são também parte de coletivos juvenis que procuram novos espaços, que permitem criar seus próprios códigos de participação na esfera pública e concebem expressões organizativas contrapostas à lógica representativa tradicional, buscando que o rechaço ao sistema de representação seja substituído por uma nova prática política (SOUSA, 2003; VALENZUELA, 2007). Estes jovens participam de coletivos anarquistas, socialistas, autonomistas, entidades de espectros variados, tendo como característica principal "o ativismo radical para construir alternativas, destruir e alterar processos e práticas do capitalismo" (SOUSA, 2002, p.2).

As produções midiáticas mais significativas que expressam este primeiro período são: o vídeo Não começou em Seattle. Não vai terminar em Quebec e o jornal Ação Direta, produzidos pelo CMI São Paulo, entre 2000 e 2001. Ambos reportaram: a campanha contra ALCA; as oficinas de Repórteres Populares realizadas pelo CMI Porto Alegre; a transmissão por uma convergência internacional de rádios livres das manifestações contra cúpula ministerial da ALCA, em Mar Del Plata; a campanha contra o fechamento de rádios comunitárias e a cobertura do Fórum Social Mundial.

O segundo ciclo inicia-se em 2003, com as revoltas do Buzu, em Salvador, e com as Revoltas da Catraca, em Florianópolis, em 2004 e 2005. O cresci- 
mento da rede CMI, aos poucos, deixa de ser vinculado às campanhas e protestos contra o capitalismo. Na América Latina, a ALCA foi engavetada em 2005 e as manifestações massivas contra os organismos multilaterais - como G8, Banco Mundial e OMC - começaram a diminuir após as leis antiterroristas serem adotadas, inicialmente pelos Estados Unidos e Europa, tornando-se mecanismos de repressão bastante eficazes aos protestos políticos.

Os voluntários e voluntárias mantêm sua múltipla militância sob os mesmos princípios político-organizacionais do primeiro ciclo. Entretanto, o principal vetor social - a questão do direito à cidade nos protestos contra os aumentos das tarifas do transporte coletivo e a campanha pela gratuidade do transporte para estudantes - torna-se, em 2005, o Movimento Passe Livre. Muitos dos voluntários e voluntárias vão atuar no CMI, no Movimento Passe Livre (MPL) e também em coletivos autônomos ligados às pautas de esquerda. Eles buscam, na radicalização dessas pautas, e por meio da ação direta, "desburocratizar" os espaços tomados pelos interesses corporativos e partidários da esquerda tradicional com vistas à conquista e manutenção de cargos na esfera governamental.

Segundo uma entrevista realizada por Santos (2010) com Harry Kipper, 22 anos - voluntário do CMI Floripa e militante do Movimento Passe livre - outro elemento de mudança no CMI de vetor nas lutas sociais juvenis foi a necessidade de obter vitórias- ainda que de forma momentânea e parcial - que influenciassem nas condições objetivas da população. Fazia-se importante, também, ações coletivas cujas motivações não fossem tão abstratas para maioria das pessoas, como o capitalismo global. Os protestos radicalizados contra o aumento das tarifas de 2004, em Florianópolis, não só pegou de surpresa a administração municipal e os empresários - ambos ciosos do poder de impor seus interesses à população - mas também à esquerda sindical e partidária.

Apesar de apoiarem circunstancialmente a Campanha pelo passe livre estudantil, organizada pela Juventude Revolução Independente ${ }^{3}$ em 2004, os partidos de esquerda e os sindicatos atribuíram à campanha um papel reformista e não deram devida importância às ações coletivas organizadas, de forma autônoma, por esses jovens das entidades estudantis e trabalhistas.

Em 2004, os primeiros dias dos protestos foram quase que exclusivamente protagonizados por estudantes do ensino médio e superior que participavam ou apoiavam as ações da Campanha pelo passe livre estudantil. As ruas tomadas por jovens de escolas públicas e particulares que viviam em bairros e realidades materiais distintas era um palco emblemático, apesar da brutalidade policial e dos seguranças do sindicato das empresas de transporte coletivo. A atmosfera democrática e rebelde estava presente nas assembleias que decidiram os rumos dos protestos, sem a interferência de lideranças de

\footnotetext{
3 A Juventude Revolução Independente (JRI) nasce de uma ruptura da Juventude Revolução da corrente trotskista $O$ Trabalho do Partido dos Trabalhadores, em 2000. A corrente que se define simplesmente revolucionária apartidária, autonomista e libertaria, deixa para trás as práticas do centralismo democrático e assume uma postura mais madura em relação à sua autonomia política, à tensão entre a organização formal dos militantes mais comprometidos e à "espontaneidade" do movimento das ruas. (SANTOS. 2010)
} 
fora do movimento; e nas passeatas e nas vaias, em resposta às tentativas de aparelhamento e capitulação por militantes de partidos. Além disso, esse espaço de luta facilitava vivenciar experiências afetivas sem a vigilância dos pais.

Além das publicações e participação dos coletivos locais nas lutas contra os aumentos da tarifa em Florianópolis e Salvador, outro trabalho do CMI que ilustra esse período foi a cobertura do caso da desocupação violenta no "Sonho Real" e a produção de um vídeo sobre o caso com o nome Sonho Real. Uma história de luta por moradia, realizado pelo coletivo local de Goiânia.

O terceiro ciclo é caracterizado por três elementos: a saída de voluntários e voluntárias dos coletivos do CMI, os problemas relacionados à defasagem técnica do site e novas convergências do CMI relacionadas às lutas sociais. Entre 2005 e 2009, a saída gradual de voluntários se explica pela condição transitória da juventude. Os voluntários e voluntárias mais antigos na rede passam a ter uma participação política mais focalizada em uma única organização, a dividirem seu tempo com o trabalho, lazer e filhos ou saírem definitivamente do CMI. Essa situação deixou lacunas significativas na rede, pois com a saída de voluntários e voluntárias perdia-se também a discussão acumulada durante o seu tempo de permanência e a experiência de atuação em rede.

Outro problema apontado por um voluntário do CMI Curitiba ${ }^{4}$ foi gerado pela rotatividade e pela desconfiança dos voluntários mais velhos com os mais novos, causando problemas que iam do desconforto durante as reuniões a uma postura centralizadora dos mais antigos em relação a atividades importantes. Por receio com a segurança e por excesso de zelo, acabavam por dar a entender aos voluntários mais novos que sua participação não era tão importante.

Os coletivos locais do CMI também enfrentaram problemas relacionados à formação de grupos de afinidades no interior dos coletivos ${ }^{5}$. Alguns superaram, por meio do diálogo e criação de novas dinâmicas de ingresso de novos voluntários; outros foram vencidos pelo esgotamento, o que implicou em um número menor de pessoas participando das atividades cotidianas da rede, o que sobrecarregou até o esgotamento algumas pessoas, muitas vezes também fragilizadas por acusações de autoritarismo decorrentes dos problemas de rotatividade de membros dos coletivos locais.

Os problemas de defasagem técnica, segundo dados coletados na lista do coletivo técnico do CMI (2010), foram motivados a partir do momento em que o gerenciador de conteúdos $\mathrm{MIR}^{6}$ - utilizado pelo CMI Brasil - parou de

\footnotetext{
$4 \quad$ Preferimos não citar o seu nome a pedido do entrevistado.

5 Esses grupos de afinidade acabam por reproduzir práticas centralistas e antidemocráticas como as que Jo Freemam (1970) descreve em A Tirania das Organizações Sem Estrutura. A ideologia da organização "sem estrutura", segundo a autora, pode proporcionar a formação de uma elite no caso um grupo de amigos, que compartilham valores, opiniões e posições; mesmo involuntariamente estes amigos estabelecem redes de comunicação, consultam, mais constantemente, se esta rede é única dentro do coletivo e, provavelmente, vai estabelecer por conta destes laços informais um poder de decisão maior do coletivo. Deste modo esta relação vai trazer duas consequências; a primeira fazer do coletivo uma "irmandade", onde só se escuta a pessoa que se gosta e não por dizer algo coerente ou importante; a segunda, de que as estruturas informais não têm a obrigação pelo grupo todo, o poder que lhe foi conferido não pode lhe ser retirado, pois não há um princípio suficientemente claro para que o descaso com o coletivo tenha um parâmetro que avalie a participação.
}

6 Nome se refere à estação espacial russa que durante 15 anos abrigou seres humanos em órbita da Terra. 
ser desenvolvido pela comunidade de software livre, ao mesmo tempo em que novas opções de publicação na internet - em plataformas corporativas - foram sendo utilizadas pelos movimentos sociais e nas ações coletivas. A facilidade de criar blogs e o uso de ferramentas de redes sociais como o facebook e o twiiter, apesar de não terem causado grandes danos às visitas ao site do CMI, aos poucos, foi se tornando um problema para a mídia alternativa, dado que estas plataformas comerciais não oferecem nenhuma segurança aos ativistas e possuem, de certa forma, uma tendência criar uma dependência do usuário, que acredita que se deixar de lado essas ferramentas e criar seu próprio veículo perderá totalmente a visibilidade.

Sobre as novas convergências de coletivos do CMI, o exemplo mais interessante é a formação do CMI Tefé, no Amazonas, em 2006. Desde a sua formação até hoje, o coletivo CMI Tefé vem desenvolvendo atividades junto a uma rádio livre - a Rádio Xibé - que foi ao ar pela primeira vez em outubro do mesmo ano, produzindo conteúdo em um site de publicação aberta, software livre, jornalismo popular, produção de vídeo e realizando oficinas com diferentes públicos. Além disso, das atividades já descritas, o CMI Tefé tem realizado coberturas de manifestações e acontecimentos locais e organizado, junto às comunidades locais e outras organizações, eventos da rede Flor da Palavra, "expressão zapatista que liga a noção de florescimento ao conceito maia de "palavra": a "palavra verdadeira" é a que vem do coração (...)" (FLOR DA PALAVRA, 2009).

O primeiro evento foi em 2006, A Flor dos Movimentos Rurais, em que durante dois dias foram exibidos filmes e realizados debates sobre as redes horizontais, zapatismo, rádios livres e ação direta. Entre os anos de 2006 e 2009, foram realizados 15 eventos Flor da Palavra, nas cidades de Campinas (SP), São Paulo (SP), Tefé (AM), Brasília (DF), Marília (SP), Cidade do México, Curitiba (PR), Maringá (PR), São José dos Pinhais (PR) e Catu (RN). Muitos deles, com participação direta de coletivos locais ou voluntários da rede CMI.

A organização dos eventos Flor da Palavra - como a campanha Existe política Além do Voto que percorreu as cidades satélites do Distrito Federal, organizada pelos coletivos do CMI, Koletivo de Resistência Anarco Punk, Ação Rebelde Dignidade Candanga, Corpus Krisis e pelo Movimento Passe Livre - nos esclarecem os pontos de conexão dos jovens com as lutas sociais em andamento. É o caso da luta contra especulação imobiliária no Santuário dos Pajés e da atuação junto ao movimento de luta por moradia.

A solidariedade entre voluntários do CMI e os militantes dos movimentos sociais e comunitários, dos quais se aproximaram ao longo dos dois primeiros ciclos, foi de certa forma um dos fatores para que a rede não se fragmentasse, apesar do refluxo de participação no interior dos coletivos. Entretanto, um dos fatores que mais colaborou para que o CMI fosse, aos poucos, perdendo a visibilidade e influência no que diz respeito ao modo de democratização da mídia, foi produto de um processo de cooptação do Estado, oportunizado por fragilidades presentes na condição juvenil e pela ambiguidade na utilização das tecnologias de informação como parte de sua organização e ativismo. 
A política de comunicação e de cultura do governo federal a partir do presidente Luiz Inácio Lula da Silva se mostra aparentemente contraditória. Enquanto na pasta da comunicação percebe-se a manutenção das concessões públicas como moeda de troca do governo com setores conservadores da sociedade, visando a manutenção de apoios políticos, na pasta da cultura, o governo avançou em relação à redistribuição de recursos para projetos de cultura popular e artísticos de forma diferenciada dos governos anteriores, os quais destinavam quase que exclusivamente o montante de suas verbas para projetos produzidos por grandes nomes das artes do país. O governo também avançou, relativamente, em direção a uma reformulação mais flexível quanto à questão da propriedade intelectual, principalmente, na gestão do ministro Gilberto Gil, incentivando a criação de uma nova economia da cultura no país, baseada no trabalho colaborativo, na utilização de tecnologias livres e na democratização do acesso à cultura e informação.

A nova economia da cultura proposta pelo governo Lula tinha como base as propostas do Movimento de Cultura Livre, nome dado às diversas formas de democratização da cultura realizadas por artistas, ativistas de comunicação, programadores, hackers, jornalistas, advogados, organizados em uma rede difusa de atores coletivos e individuais, utilizando principalmente as novas tecnologias digitais, para reduzir o papel do intermediário nos processos de criação, consumo e difusão dos bens culturais (SANTOS, 2010). O Movimento de Cultura Livre possui uma genealogia ligada às diversas práticas políticas da contracultura, da cultura de oposição e do software livre, que ganharam visibilidade a partir dos anos 2000, período que corresponde ao início de um maior tensionamento entre os sujeitos coletivos emergentes em prol do compartilhamento dos bens culturais e da informação e os atores hegemônicos governos e corporações - e suas medidas em defesa da propriedade intelectual e restrição à livre informação.

Entretanto, há uma ambiguidade no interior do Movimento de Cultura Livre desde os primeiros tempos do software livre. A palavra free, para Richard Stallman, tem a ver com as quatro liberdades do copyleft $t^{7}$, e não com a gratuidade, algo que abre caminhos para exploração pelo modelo de negócios da indústria criativa. O termo "indústria criativa" define a sustentação do modelo de negócio, onde a criatividade é seu elemento central, sendo que ela é necessária para produção de propriedade intelectual e a subsequente criação de commodities e comercialização. A cultura comprimida, como sinônimo de bens culturais nesse modelo de negócio, adquire valor não por suas propriedades físicas ou materiais, e sim pela carga dos sentidos socialmente compartilhados que carregam.

O modelo de negócios capitalista usa de nova retórica, ressaltando os imperativos da originalidade e da criatividade; celebra o culto das mudanças, das rupturas e da inovação, relacionada à passagem da sociedade industrial

7 a) a liberdade de executar o programa para qualquer propósito. b) a liberdade de estudar como o programa funciona, e para isso o acesso ao código-fonte é um pré-requisito básico; c) a liberdade de redistribuir cópias de modo a beneficiar outras pessoas. d) a liberdade de aperfeiçoar o programa e liberar suas melhorias (SANTOS, 2010) 
para a sociedade pós-industrial (CASTELLS, 1999). Contudo, a massificação da indústria cultural coexiste e disputa espaço com a difusão fragmentada da industrial criativa, sem ruptura com o capitalismo. Em certos casos, os incentivos federais foram bem sucedidos, proporcionando a melhoria nas condições estruturais e expansão de projetos de cultura popular, inclusão digital e cultura livre e a redefinição de políticas públicas. Mas houve também grandes distorções, como o favorecimento de certos grupos e projetos ligados aos partidos governistas em editais de incentivo à cultura e na definição da coordenação da imensa rede de projetos ligado às políticas governamentais.

No início, a iniciativa governamental de estímulo à cultura livre atraiu muitos ativistas ligados aos movimentos autônomos para dentro dos projetos de organizações não governamentais, financiados por leis de incentivo à cultura e patrocínios empresariais. Muitos destes ativistas eram jovens que estavam ingressando numa condição de trabalhadores e que viram nas ONGs e projetos governamentais a possibilidade de "hackear o sistema", ou seja, utilizar a estrutura dos projetos e os recursos financeiros para favorecer o ativismo autônomo fazendo o que gostavam. A ideia de hackear o sistema, em um trabalho aparentemente menos penoso que na iniciativa privada ou diretamente como funcionário público, aos poucos foi enfraquecendo o ativismo autônomo nos meios digitais e no movimento estudantil independente - bases de suporte técnico e de renovação do Centro de Mídia Independente e de outras iniciativas anticapitalistas.

Os jovens que haviam iniciado sua trajetória política e se capacitado tecnicamente nos coletivos autônomos migram suas energias para dentro de uma estrutura de gerenciamento que possui contornos, favorecendo a cooptação das alternativas radicais pelo capitalismo informacional. No entanto, a perda da autonomia política, quando se encaram antigos inimigos históricos da esquerda - como a Fundação Ford, Rede Globo de Televisão ou empresas como o Vale do Rio Doce, e Petrobras, como grandes mecenas da cultura - é um dos pontos da questão, mas não o único. Há outros dois processos: uma postura acrítica de parte dos ativistas do Movimento de Cultura Livre com as medidas autoritárias tomadas pelo governo, e a exaltação do modelo de negócios da indústria criativa, como se fosse sinônimo de cultura livre.

A postura acrítica a que nos referimos é tendência inevitável a silenciar diante da supressão de direitos individuais e coletivos, da repressão dos protestos políticos das classes pobres e movimentos sociais. Ou, quando não, era interessante demonstrar que o nacional desenvolvimentismo das políticas governamentais favorece determinadas elites em detrimento da devastação ambiental e consequências sociais absurdamente insustentáveis como a Usina de Belo Monte e o despejo forçado de comunidades para as obras das Olimpíadas e Copa do Mundo. O silêncio não pode ser visto como mero oportunismo, e sim como duas faces da mesma moeda: a visão fragmentada das políticas governamentais, como se não fossem produto do jogo de alianças, troca de favores entre o governo federal e elites conservadoras nas instituições públicas 
e privadas, e o fetiche sobre as possibilidades oferecidas pela tecnologia de informação.

Muitos coletivos de cultura livre que, de certa forma, exaltavam o modelo de negócios da indústria criativa, se propunham a ser uma forma de ativismo diferenciado da esquerda tradicional, caracterizada por eles como incapazes de fazer uma leitura das novas possibilidades inerentes às tecnologias livres. Entretanto, se a crítica à esquerda tradicional pode ser parcialmente verdadeira, o modelo da indústria criativa, que exalta uma ideologia capitalista e liberal travestida de novo ativismo autônomo, não é consenso entre todos os sujeitos do Movimento de Cultura Livre, nem mesmo nos projetos financiados pelo governo.

Ativistas dos coletivos, como o coletivo luso-brasileiro Passa Palavra, de redes anticapitalistas como CMI e ativistas do Rizoma de rádios livres nos últimos anos, têm exaustivamente denunciado as distorções, desigualdades e a ideologia do capitalismo informacional no interior do movimento de mídia radical e do ativismo autônomo em encontros intitulados Cultura Livre e Capitalismo e por meio de suas publicações.

Apesar de ser muito cedo para fazer um prognóstico dos rumos do ativismo juvenil na mídia radical alternativa, o intenso debate em torno desses encontros e publicações têm mobilizado diversos setores ligados à comunidade ativista e à academia.

\section{Notas (in) conclusivas}

Ao longo da exposição da trajetória da rede CMI no Brasil, é possível visualizar elementos relacionados às novas interações e correlações do ativismo juvenil autonomista e às concepções sobre a relação entre democracia e sua forma de participaçzão política. Um dos elementos é a múltipla militância dos jovens que participam da mídia radical no Brasil e nos coletivos autônomos, e a construção de um ideário que mistura práticas da contracultura e a radicalização das pautas de esquerda mobilizando teses de correntes autonomistas, anarquistas e do marxismo heterodoxo.

Os jovens voluntários e voluntárias buscam a participação na ação direta em novas formas do fazer político, sem desprezar a necessidade do diálogo com outros setores da sociedade civil organizada, em uma crítica radical ao modelo de representação política. O espaço institucional é um lugar "onde se pode vencer batalhas, mas não será onde se vencerá a guerra", como disse Paíque, 23 anos, voluntário do CMI Distrito Federal, graduando em Antropologia pela Universidade de Brasília (UnB), ativista do Movimento dos Trabalhadores Desempregados, do Movimento Passe Livre (MPL) e do Comitê de Solidariedade a Cesare Batisti.

Retomar os espaços públicos colonizados por interesses privados perpassa tanto as suas publicações, mas também, e principalmente, as práticas cotidianas na forma de tomar decisão, solidarizar-se e capacitar ativistas e militantes de movimentos comunitários e sociais para serem produtores de informação. Esta 
é matéria-prima fundamental para que os sujeitos imersos nas ações coletivas tomem decisões ou se reconheçam mutuamente para contar e sentir-se parte da mesma história de rebeldia.

O elemento de contestação na mídia radical torna-se propositivo com a construção de redes, onde a democratização da informação não tem um fim em si mesmo, mas é, sim, um dos elementos da democratização da sociedade por princípios que mobilizam uma série de recursos imateriais e códigos culturais para criar comunidades de sentido e uma consciência desatada dos sentidos hegemônicos. Entretanto, é possível perceber que as práticas da mídia alternativa têm sido engolidas cada vez mais rápido pelo capitalismo informacional, já que a flexibilidade e o trabalho colaborativo - cernes da cultura livre - são disputados também pelas empresas e iniciativas governamentais, como no capitalismo informacional. Ao longo do estudo, nos deparamos com um cenário em os investimentos governamentais para fortalecimento do modelo de negócios da indústria criativa proporcionou uma série de efeitos contraditórios nos espaços de atuação de coletivos como CMI. Isso não significa dizer que a participação política dos jovens tenha perdido seu potencial libertário. Pelo contrário, ao mesmo tempo em que o capitalismo informacional engole as práticas, interações e correlações de força aparecem e buscam quebrar os mecanismos onde o "velho" vem vestido de "novo".

\section{Referências bibliográficas}

BAUMAN. Zigmund. Globalização: as consequências humanas. Rio de Janeiro: Zahar, 1999.

BEHLING, M. Das Wachstum des Indymedia-Netzwerks: Das erste global agierende alternative Mediennetzwerk. Perspektive'89.[S.1.] Apr. 2006. Disponível em: < $\underline{\text { http://www.perspekti- }}$ ve89.com/> Acesso em: 23 abr. 2010.

BOIDO, Pablo. Indymedia, Argentina. OURmedia \& Nuestros Médios. Porto Alegre: 2003 Disponível em: <http://mediaprof.org/ourmedia/omwebsite/papers/om2003/Boido_OM3.pdf $>$ Acesso em 17 mar. 2010.

BRECHT, Bertold. Poemas (1913-1956). Disponível em: < http://www.fla.matrix.com.br/ticiano/brecht.htm> Acesso em: 10 jun. de 2012.

CARTAS E COMUNICADOS DEL EZLN. Subcomandante Marcos: ya no es tan lejano que sea posible un cambio democrático. Entrevista a Marcos, 18 de março de 1994. Disponível em: $<$ http://palabra.ezln.org.mx/.> Acesso em: 25 jun. 2009.

CASTELLS, Manuel. O poder da identidade. São Paulo: Paz e Terra, 1999.

CECEÑA, Ana Esther. Los diferentes planos de construcción de la hegemonía. In: GAMBINA, J. (Comp.). La globalización económico-financiera y el impacto en América Latina - estrategias de regulación y respuestas sociales y políticas del movimiento popular. Buenos Aires: CLACSO, 2003. 
DOWNING, John D. H. Mídia radical - rebeldia nas comunicações e movimentos sociais. São Paulo: SENAC, 2003.

FEIXA, Carles. O quarto do adolescente na era digital. In: COSTA, Marcia R.; SILVA, Elizabeth M. (Orgs.) Sociabilidade juvenil e cultura urbana. São Paulo: Editora PUC-SP, 2006, p. $79-110$.

FLOR DA PALAVRA. Rizoma Flor da Palavra: modesta contribuição a um caleidoscópio mundial. [S.l., s.n.], [2009] Disponível em: $<$ http://flordapalavra.noblogs.org/flor-da-palavra/ $>$ Acesso em: 17 mai. 2012.

FREEMAN, Jo. A tirania das organizações sem estrutura. [S.1.]: Centro de Mídia Independente. Disponível em: <www.nodo50.org. > Acesso em: 17 mai. 2010. (Artigo de 1970)

GROPPO, Luis Antônio. Uma onda mundial de revoltas: movimentos estudantis de 1968. Piracicaba: UNIMEP, 2005.

HARDT, Michael; NEGRI, Antônio. Império. 2.ed. Rio de Janeiro: Record, 2001

HARVEY, David. Organizando para a transição anticapitalista. Margem esquerda. São Paulo: Boitempo, 2010.

HILSENBECK F. Democracia e governos autônomos - uma reflexão a partir da experiência do Exército Zapatista de Libertação Nacional. Mediações: Revista de Ciências Sociais, São Paulo, v. 10, no. 2, p.55-73, 2005.

JURIS, Jeffrey. S. Indymedia: de la Contra-Información a la Utopía Informacional. In: MARÍ SÁEZ, Victor Manuel (Coord.). La Red es de todos. Cuando los Movimientos Sociales se Apropian de la Red. Madrid: Editorial Popular, 2004. p.154-177.

LIBERATO, Leo Vinícius Maia. Expressões contemporâneas de rebeldia: poder e fazer da juventude autonomista. Tese (Doutorado em Sociologia Política). Universidade Federal de Santa Catarina, Florianópolis, 2006.

LUDD, Ned (Org.). Urgência das ruas. Black Bloc, Reclaim the Streets e os Dias de Ação Global. São Paulo: Conrad, 2002

MELUCCI, Alberto. Ación Colectiva, Vida Cotidiana Y Democracia. México: El Colegio Del México, 1999.

PASSA PALAVRA. Especial 9 anos de CMI-Brasil. 21 dez. 2009. Disponível em: < http:// passapalavra.info/?p=16807>. Acesso em: 18 mai. 2010.

SANTOS, Boaventura de Sousa. Trabalhar o Mundo. Os caminhos do novo internacionalismo operário. Rio de Janeiro: Civilização Brasileira, 2005.

SANTOS, Carlos André dos. A Rebeldia por trás das lentes - Participação política juvenil no Centro de Mídia Independente no Brasil. Dissertação (Mestrado em Sociologia Política) Centro de Filosofia e Ciências Humanas, Programa de Pós-graduação em Sociologia Política, Universidade Federal de Santa Catarina, Florianópolis, 2010. 
SENETT, Richard. A corrosão do caráter: consequências pessoais do trabalho no novo capitalismo. 14 ed. Rio de Janeiro: Record, 2009.

SOUSA, Janice Tirelli Ponte de. Os jovens anticapitalistas e a ressignificação das lutas coletivas. CONGRESSO DE SOCIOLOGIA, 11, Campinas. Anais...Campinas: Unicamp, 2003.

VALENZUELA FUENTES, Katia. Colectivos juveniles: ¿inmadurez política o afirmación de otras políticas posibles? Ultima décad., Santiago, v. 15, n. 26, p. 31-52, jul. 2007.

Recebido em: 18/06/2013

Revisão em: 18/06/2013

Aceite em: 08/09/2013

Carlos André dos Santos possui Licenciatura e Bacharelado em Ciências Sociais pela Universidade Federal de Santa Catarina e Mestrado em Sociologia Política pela Universidade Federal de Santa Catarina. É professor de Sociologia no EEB Cecília Rosa Lopes, São José/SC. Endereço para correspondência: Rua Julio José Gonçalves. No. 58. Barra da Lagoa. Florianópolis/SC, Brasil. CEP: 88061-375 E-mail: cazeradio@gmail.com 